\title{
EUROPEAN RESPIRATORY journal
}

FLAGSHIP SCIENTIFIC JOURNAL OF ERS

\section{Early View}

Research letter

\section{High-dose versus low-dose prednisolone in symptomatic patients with post-COVID-19 diffuse parenchymal lung abnormalities: an open-label, randomised trial (Acronym: COLDSTER)}

Sahajal Dhooria, Shivani Chaudhary, Inderpaul Singh Sehgal, Ritesh Agarwal, Siddhant Arora, Mandeep Garg, Nidhi Prabhakar, Goverdhan Dutt Puri, Ashish Bhalla, Vikas Suri, Lakshmi Narayana Yaddanapudi, Valliappan Muthu, Kuruswamy Thurai Prasad, Ashutosh Nath Aggarwal

Please cite this article as: Dhooria S, Chaudhary S, Sehgal IS, et al. High-dose versus low-dose prednisolone in symptomatic patients with post-COVID-19 diffuse parenchymal lung abnormalities: an open-label, randomised trial (Acronym: COLDSTER). Eur Respir J 2021; in press (https://doi.org/10.1183/13993003.02930-2021).

This manuscript has recently been accepted for publication in the European Respiratory Journal. It is published here in its accepted form prior to copyediting and typesetting by our production team. After these production processes are complete and the authors have approved the resulting proofs, the article will move to the latest issue of the ERJ online.

Copyright (CThe authors 2021. This version is distributed under the terms of the Creative Commons Attribution Non-Commercial Licence 4.0. For commercial reproduction rights and permissions contact permissions@ersnet.org 


\title{
High-dose versus low-dose prednisolone in symptomatic patients with post-COVID-19 diffuse parenchymal lung abnormalities: an open- label, randomised trial (Acronym: COLDSTER)
}

\author{
${ }^{1}$ Sahajal Dhooria* \\ ${ }^{2}$ Shivani Chaudhary* \\ ${ }^{3}$ Inderpaul Singh Sehgal \\ ${ }^{4}$ Ritesh Agarwal \\ ${ }^{5}$ Siddhant Arora \\ ${ }^{6}$ Mandeep Garg \\ ${ }^{7}$ Nidhi Prabhakar \\ ${ }^{8}$ Goverdhan Dutt Puri \\ ${ }^{9}$ Ashish Bhalla \\ ${ }^{10}$ Vikas Suri \\ ${ }^{8}$ Lakshmi Narayana Yaddanapudi \\ ${ }^{3}$ Valliappan Muthu \\ ${ }^{3}$ Kuruswamy Thurai Prasad \\ ${ }^{4}$ Ashutosh Nath Aggarwal
}

*These authors contributed equally to the manuscript and may be considered as first authors.

${ }^{2}$ Clinical Research Co-ordinator, ${ }^{3}$ Assistant Professor, ${ }^{1}$ Associate Professor, and ${ }^{4}$ Professor, Department of Pulmonary Medicine

${ }^{7}$ Assistant Professor, and ${ }^{6}$ Professor, Department of Radiodiagnosis and Imaging

${ }^{8}$ Professor, Department of Anaesthesia and Intensive Care

${ }^{5}$ Junior Resident, ${ }^{10}$ Additional Professor, and ${ }^{9}$ Professor, Department of Medicine

Postgraduate Institute of Medical Education and Research (PGIMER), Chandigarh, India

\section{Address for correspondence}

Dr. Sahajal Dhooria MD, DM

Associate Professor

Department of Pulmonary Medicine

Postgraduate Institute of Medical Education and Research

Chandigarh-160012, India

Phone: +91 1722756827

Fax: +91 1722748215

Email: sahajal@gmail.com

Funding: none 


\section{Competing interest statements}

SD: Conflicts of interest- none; financial disclosures- none SC: Conflicts of interest- none; financial disclosures- none ISS: Conflicts of interest- none; financial disclosures- none RA: Conflicts of interest- none; financial disclosures- none SA: Conflicts of interest- none; financial disclosures- none MG: Conflicts of interest- none; financial disclosures- none NP: Conflicts of interest- none; financial disclosures- none GDP: Conflicts of interest- none; financial disclosures- none $A B$ : Conflicts of interest- none; financial disclosures- none VS: Conflicts of interest- none; financial disclosures- none LNY: Conflicts of interest- none; financial disclosures- none VM: Conflicts of interest- none; financial disclosures- none KTP: Conflicts of interest- none; financial disclosures- none ANA: Conflicts of interest- none; financial disclosures- none 
TAKE HOME MESSAGE

High-dose prednisolone may not be superior to a low-dose regimen given over 6 weeks in improving the clinical, physiologic, and radiologic outcomes, or the health-related quality of life in symptomatic post-COVID-19 diffuse parenchymal lung abnormalities. 
In some patients, respiratory symptoms and imaging abnormalities persist after acute coronavirus disease 2019 (COVID-19) pneumonia.[1-3] The chest computed tomography (CT) generally shows diffuse parenchymal lung abnormalities consistent with organising pneumonia (OP).[4] It has also been proposed that the novel SARS-CoV-2 could act as a trigger to exalt the presence of pre-existing interstitial lung abnormalities encountered in the general population, especially in smokers. Previous observational studies reported improvement with glucocorticoids in symptomatic patients with post-COVID-19 diffuse parenchymal lung abnormalities (PC-DPLAS).[4-6] A recent guideline recommended glucocorticoids for treating PC-DPLAS.[3] However, there are no randomised controlled trials on therapies for this condition.

We conducted an investigator-initiated, single-centre, open-label, parallel-group, randomised, superiority trial of two doses of prednisolone at our Institute. After Institute Ethics Committee approval and protocol registration (COLDSTER trial; clinicaltrials.gov;

NCT04657484), we included consecutive, consenting subjects aged $\geq 18$ years at 3-8 weeks from acute COVID-19 symptom onset, if they had: (i) COVID-19 diagnosed by real-time reverse transcriptase polymerase chain reaction or COVID-19 antigen; (ii) persistent dyspnoea (modified Medical Research Council scale $[\mathrm{mMRC}] \geq 2$ ), or resting hypoxaemia (oxygen saturation $\leq 94 \%$ ), or exertional desaturation ( $\geq 4 \%$ fall in oxygen saturation on exercise) at screening; and, (iii) diffuse abnormalities involving $\geq 20 \%$ of the lung parenchyma on semiquantitative assessment on thin-section $(1.0 \mathrm{~mm})$ CT. We excluded subjects with any of the following: (i) ongoing intensive care; (ii) pre-existing structural lung disease; (iii) pregnancy or lactation; and (iv) contraindication for prednisolone. 
We allocated subjects 1:1 by computer-generated simple randomisation (allocation concealment in consecutively numbered sealed opaque envelopes) to receive either high-dose (40 mg/day for one week, followed by $30 \mathrm{mg} /$ day for one week, $20 \mathrm{mg} /$ day for two weeks, and $10 \mathrm{mg} /$ day for two weeks) or low-dose (10 mg/day of prednisolone for six weeks) prednisolone. We assessed the resting oxygen saturation, dyspnoea severity (mMRC scale), and six-minute walk test (6MWT) at randomisation. We monitored for treatment compliance and adverse effects telephonically at two and four weeks. At six weeks, we performed the following assessments: resting oxygen saturation, dyspnoea severity (mMRC scale and Functional Assessment of Chronic Illness Therapy 10-item dyspnoea questionnaire), 6MWT, spirometry, thin-section CT chest, respiratory health status (King's brief ILD questionnaire), health-related quality of life (HRQoL) using short-form 36 (SF-36) questionnaire, treatment compliance, and treatment-related adverse effects [7-11] We assessed the radiologic response both by scoring for resolution of overall diffuse lung abnormalities and a systematic semiquantitative scoring for individual radiologic abnormalities (Table 1 legend).[12, 13]

We evaluated all outcomes six weeks after randomisation. The primary outcome was the proportion of subjects with a complete radiologic response ( $\geq 90 \%$ reduction in diffuse lung abnormalities) on CT. The key secondary outcomes included the proportion of subjects with a complete or good radiologic response ( $\geq 50 \%$ resolution in diffuse lung abnormalities), percentage of the predicted forced vital capacity (FVC), improvements in the resting oxygen saturation and dyspnoea severity, and adverse effects. 
Between December 2020 and June 2021, we screened 290 subjects and randomised 65 to each group. The major reasons for exclusion were mild lung abnormalities $(n=82)$, contraindications to prednisolone $(n=27)$, consent refusal $(n=23)$, and others $(n=28)$. The study groups had similar baseline characteristics with a mean age of 57 years, 32\% women, and $73 \%$ subjects with at least one comorbidity. All subjects were hospitalised for acute COVID-19 illness. About $98 \%$ had either critical or severe disease according to the World Health Organization criteria; $43 \%$ received either mechanical ventilation or high-flow nasal oxygen. Most (76.2\%) subjects were randomised after hospital discharge (median of 36 days from acute COVID-19 symptom onset and 15 days since hospital discharge). At randomisation, the subjects had a median mMRC dyspnoea score of 3; $88 \%$ of subjects had exertional (or resting) hypoxemia with $27 \%$ requiring supplemental oxygen. About $91 \%$ had OP pattern on CT chest. The cumulative glucocorticoid dose received during acute COVID-19 management (median dose, 505 mg prednisolone equivalent) was similar between the study groups $(p=0.16)$.

Sixty-one (93.8\%) and 60 (92.3\%) subjects completed six-week follow-up in the highdose and low-dose groups, respectively (compliance by cumulative dose, $96.8 \%$ and $96.2 \%$ ). We found a complete radiologic response in $16(24.6 \%)$ and 12 (18.5\%) subjects in the high-dose and low-dose groups, respectively $(p=0.39)$. Fifty-five (84.6\%) and $52(80.0 \%)$ subjects had a complete or good radiologic response in the respective groups $(p=0.49)$. The mean percentagepredicted FVC at six weeks was similar (high-dose: 71.1, low-dose: $67.4 ; p=0.21$ ). The median (interquartile range) improvements in resting oxygen saturation (high-dose: 2 [0-6], low-dose: 2 [1-6], $p=0.91$ ) and mMRC scale (high-dose: 1 [1-2], low-dose: 2 [1-2], $p=0.52$ ) were similar. Only one subject (high-dose group) required supplemental oxygen at six weeks. The other secondary 
and exploratory outcomes also did not differ between the study groups (Table 1). The outcomes did not differ by study group allocation in any of the analysed subgroups based on age (<60 years vs. $\geq 60$ years), sex, comorbidity (none vs. any), body weight (<80 kg vs. $\geq 80 \mathrm{~kg}$ ), duration since COVID-19 onset (four weeks or less vs. more than four weeks), cumulative prednisolone dose before randomization ( $<500 \mathrm{mg}$ vs. $\geq 500 \mathrm{mg}$ ), peak oxygen requirement during hospitalisation (fraction of inspired oxygen $\leq 0.5$ vs. $>0.5$ ), mechanical ventilation, and dyspnoea severity (mMRC grade 2 or less vs. grade 3 or 4).

The incidence of treatment-related adverse effects was similar between the study groups (Table 1). There were no deaths. Four infections occurred (pulmonary tuberculosis, tracheostomy site infection, recurrent symptomatic acute COVID-19 in the high-dose, and an uncomplicated urinary tract infection in the low-dose group); all responded to appropriate treatment.

To our knowledge, this is the first randomised trial of any therapy for PC-DPLAS. A complete radiologic response was achieved in only $21 \%$ of subjects; this proportion lies in the higher range of early imaging outcomes previously reported in PC-DPLAS.[13-15] Dyspnoea was reduced by the minimal clinically important difference ( $\geq 1 \mathrm{mMRC}$ point) in $92 \%$ of subjects, similar between the study groups. We also found significant improvements in oxygen saturation and the six-minute walk distance in both the groups. Glucocorticoid therapy was, however, not without harm; $74 \%$ of subjects developed at least one adverse effect. Even in the low-dose group, about $29 \%$ and $22 \%$ patients developed hyperglycaemia and hypertension, respectively. 
The management of PC-DPLAS remains unclear. Many physicians adopt a 'wait-and-see' approach, administering glucocorticoids, if at all, to patients whose symptoms or hypoxaemia persist beyond several weeks to months. $[4,6]$ Contrarily, several physicians prescribe prolonged high-dose glucocorticoids early in the course of PC-DPLAS.[5] Previously, Segala et al. treated 10 patients with persistent respiratory failure beyond three weeks after acute COVID19 symptom onset with high-dose intravenous methylprednisolone and observed significant improvements in oxygenation.[6] Myall et al. treated 30 patients with persistent symptoms and a radiologic OP pattern with medium-dose prednisolone an average of 11 weeks after symptom onset and reported significant clinico-physiologic response.[4] We administered prednisolone at an average of five weeks from acute COVID-19 symptom onset (about two weeks from discharge) to patients with PC-DPLAS with considerable ongoing symptoms, oxygenation defects, and significant residual radiologic abnormalities. We observed similar improvement as previous studies even with low-dose prednisolone.[4, 6]

An important limitation of the study is the lack of a placebo arm. Nevertheless, we attempted our best to exclude patients with only mild PC-DPLAS. Our inclusion criteria, our significant exclusion rate, and the baseline radiologic and physiologic characteristics of our study subjects reflect our attempts to include only patients with persistent and severe PCDPLAS. Yet, our study cannot answer the question of whether glucocorticoids are required at all for treating PC-DPLAS. It is plausible that our subjects, although significantly symptomatic, could have improved spontaneously without any glucocorticoid therapy. However, our study does indicate that a lower glucocorticoid dose may be sufficient once a decision is made to 
treat persistent PC-DPLAS. Other limitations include a single study centre, small sample size, short follow-up, and unavailability of other pulmonary function tests such as diffusion capacity. In conclusion, we did not find high-dose prednisolone better than low-dose prednisolone in improving the clinical, radiologic, physiologic, and HRQOL outcomes in PCDPLAS. A placebo-controlled trial of glucocorticoids is required to better inform clinical practice for treating PC-DPLAS. 
Table 1. Study outcomes assessed at six weeks

\begin{tabular}{|c|c|c|c|c|}
\hline & $\begin{array}{l}\text { High-dose } \\
\text { prednisolone } \\
\text { (n=65) }\end{array}$ & $\begin{array}{l}\text { Low-dose } \\
\text { prednisolone } \\
\text { (n=65) }\end{array}$ & $\begin{array}{l}\text { Mean difference } \\
\text { ( } 95 \% \text { confidence } \\
\text { intervals) }\end{array}$ & $\begin{array}{l}P \\
\text { value }\end{array}$ \\
\hline \multicolumn{5}{|l|}{ Primary outcome } \\
\hline Complete radiologic response $^{1}$ & $16(24.6)$ & $12(18.5)$ & $\begin{array}{l}-0.06(-0.20 \\
0.08)\end{array}$ & 0.39 \\
\hline \multicolumn{5}{|l|}{ Key secondary outcomes } \\
\hline $\begin{array}{l}\text { Complete/good radiologic } \\
\text { response }^{1}\end{array}$ & $55(84.6)$ & $52(80.0)$ & $\begin{array}{l}-0.05(-0.18 \\
0.09)\end{array}$ & 0.49 \\
\hline Forced vital capacity, \%predicted ${ }^{2}$ & $71.1 \pm 16.3$ & $67.4 \pm 14.8$ & $-3.7(-9.4,2.0)$ & 0.21 \\
\hline Improvement in resting $\mathrm{SpO}_{2}{ }^{3}, \%$ & $2(0-6)$ & $2(1-6)$ & & 0.91 \\
\hline $\begin{array}{l}\text { Improvement in dyspnoea, } \\
\mathrm{mMRC}^{3}\end{array}$ & $1(1-2)$ & $2(1-2)$ & & 0.52 \\
\hline$\geq 1$ point improvement ${ }^{3}, \mathrm{n}(\%)$ & $56(91.8)$ & $56(93.3)$ & $0.02(-0.09,0.12)$ & 1.00 \\
\hline \multicolumn{5}{|l|}{ Other secondary outcomes } \\
\hline Good composite response ${ }^{1}$ & $10(15.4)$ & $10(15.4)$ & $0(-0.13,0.13)$ & 1.00 \\
\hline Oxygen desaturation on exercise ${ }^{3}$ & $30(52.6)$ & $30(50.8)$ & $\begin{array}{l}-0.02(-0.19 \\
0.16)\end{array}$ & 0.85 \\
\hline $\begin{array}{l}\text { Score on the FACIT-Dyspnea } \\
\text { scale }^{3}\end{array}$ & $45.5 \pm 11.4$ & $43.3 \pm 9.8$ & $-2.2(-6.0,1.6)$ & 0.25 \\
\hline K-BILD total score ${ }^{3}$ & $65.6 \pm 13.7$ & $64.9 \pm 15.6$ & $-0.7(-5.9,4.6)$ & 0.79 \\
\hline \multicolumn{5}{|l|}{ Short form-36 component scores ${ }^{3}$} \\
\hline Physical functioning & $59.4 \pm 26.3$ & $62.9 \pm 28.5$ & $3.5(-6.4,13.4)$ & 0.49 \\
\hline Role limitation-physical & $61.5 \pm 23.1$ & $58.3 \pm 27.9$ & $-3.2(-12.4,6.0)$ & 0.50 \\
\hline Role limitation-emotional & $74.9 \pm 30.8$ & $69.4 \pm 35.9$ & $-5.5(-17.5,6.5)$ & 0.38 \\
\hline Vitality & $59.7 \pm 18.1$ & $59.6 \pm 20.9$ & $-0.1(-7.1,6.9)$ & 0.98 \\
\hline Mental health & $71.8 \pm 17.7$ & $68.6 \pm 19.6$ & $-3.2(-9.9,3.5)$ & 0.35 \\
\hline Social functioning & $76.4 \pm 25.4$ & $69.2 \pm 29.9$ & $-7.2(-17.2,2.8)$ & 0.15 \\
\hline Bodily pain & $75.9 \pm 22.0$ & $72.5 \pm 25.8$ & $-3.4(-12.0,5.2)$ & 0.43 \\
\hline General health & $63.9 \pm 18.7$ & $61.6 \pm 19.9$ & $-2.3(-9.3,4.7)$ & 0.51 \\
\hline \multicolumn{5}{|l|}{ Exploratory outcomes } \\
\hline Six-minute walk distance, ${ }^{4}$ meters & $349 \pm 93$ & $318 \pm 129$ & $-31.0(71.4,9.4)$ & 0.15 \\
\hline $\begin{array}{l}\text { Improvement in 6MWD, } \\
\text { meters }\end{array}$ & $86(33-128)$ & $70(43-170)$ & & 0.55 \\
\hline \multicolumn{5}{|l|}{ Change in chest CT scores ${ }^{3,6}$} \\
\hline Ground glass opacities & $-1.01 \pm 1.63$ & $-0.53 \pm 1.45$ & $0.48(-0.08,1.04)$ & 0.09 \\
\hline Consolidation & $-1.16 \pm 0.88$ & $-1.13 \pm 1.10$ & $0.03(-0.33,0.39)$ & 0.88 \\
\hline Reticulation & $-0.08 \pm 0.85$ & $-0.02 \pm 0.80$ & $0.06(-0.24,0.36)$ & 0.71 \\
\hline Parenchymal bands & $0.14 \pm 0.77$ & $0.28 \pm 0.87$ & $0.14(-0.16,0.44)$ & 0.35 \\
\hline Traction bronchiectasis & $0.36 \pm 1.13$ & $0.37 \pm 1.22$ & $0.01(-0.41,0.43)$ & 0.98 \\
\hline \multicolumn{5}{|l|}{ Adverse effects, ${ }^{1}$ n (\%) } \\
\hline Any & $46(70.8)$ & 50 (76.9) & $0.06(-0.09,0.21)$ & 0.55 \\
\hline
\end{tabular}




\begin{tabular}{|c|c|c|c|c|}
\hline Hyperglycaemia & $21(32.3)$ & $19(29.2)$ & $\begin{array}{l}-0.03(-0.19 \\
0.13)\end{array}$ & 0.20 \\
\hline Hypertension & $15(23.1)$ & $14(21.5)$ & $\begin{array}{l}-0.02(-0.16 \\
0.13)\end{array}$ & 0.83 \\
\hline Cushingoid habitus & $13(20.0)$ & $13(20.0)$ & $0(-0.13,0.13)$ & 1.00 \\
\hline Fatigue & $9(13.8)$ & $13(20.0)$ & $0.06(-0.07,0.19)$ & 0.48 \\
\hline Weight gain (>10\% of baseline) & $4(6.2)$ & $5(7.7)$ & $0.02(-0.08,0.11)$ & 1.00 \\
\hline Dyspepsia & $3(4.6)$ & $7(10.8)$ & $0.06(-0.04,0.16)$ & 0.19 \\
\hline Others ${ }^{7}$ & $19(29.2)$ & $27(41.5)$ & $0.12(-0.04,0.28)$ & 0.20 \\
\hline
\end{tabular}

6MWD-six-minute walk distance, CT-computed tomography, FACIT-Functional Assessment of Chronic Illness Therapy, FLT-functional limitation, K-BILD-King's Brief Interstitial Lung Disease, mMRC-modified Medical Research Council, $\mathrm{SpO}_{2}$-oxygen saturation

The values represent either mean \pm standard deviation or median (interquartile range), unless otherwise specified.

${ }^{1}$ Outcomes presented for all subjects (65 in each group) with the worse outcomes assumed for those who were lost to follow up.

${ }^{2} 59$ subjects in the high-dose group and 57 in the low-dose group could perform spirometry. ${ }^{3}$ Outcomes reported for patients who completed follow-up (high-dose group: 61, low-dose group: 60).

${ }^{4} 57$ and 59 subjects could perform the six-minute walk test at six weeks in the high-dose and low-dose groups, respectively.

${ }^{5}$ Paired data available for six-minute walk test for 44 (high-dose group) and 37 (low-dose group) subjects.

${ }^{6}$ Ground-glass opacities, consolidation, reticulation, and parenchymal bands were scored semiquantitatively in each lobe (right upper lobe, right middle lobe, right lower lobe, left upper lobe/lingula, and left lower lobe) on CT chest. A score of 0 indicates no involvement, 1 represents $<5 \%$ of lobe involved (present but minimal), 2 reflects 5-25\%, 3 indicates $25-49 \%, 4$ signifies $50-75 \%$, and 5 denotes $>75 \%$ involvement. For each feature, the lobe scores were summed and divided by 5 to obtain an average (scale of 0 to 5 ), indicating the proportion of the total lung parenchyma showing the feature. Traction bronchiectasis was scored as absent (0) or present (1) for each lobe. The total score for traction bronchiectasis was calculated by summing up the respective scores for the five lobes.

7Other adverse effects (rarer events with less than 10 events in both the groups) included skin thinning and bruising, insomnia, muscular weakness, mood changes, abdominal pain, infection, headache, visual disturbance, dysgeusia, hypertrichosis, and acne. 


\section{REFERENCES}

1. Montani D, Savale L, Beurnier A, Colle R, Noel N, Pham T, Monnet X, Humbert M. Multidisciplinary approach for post-acute COVID-19 syndrome: time to break down the walls. Eur Respir J 2021: 58: 2101090. doi: 2101010.2101183/13993003.13901090-13992021.

2. Garg M, Maralakunte M, Garg S, Dhooria S, Sehgal I, Bhalla AS, Vijayvergiya R, Grover S, Bhatia V, Jagia P, Bhalla A, Suri V, Goyal M, Agarwal R, Puri GD, Sandhu MS. The Conundrum of 'Long-COVID-19': A Narrative Review. Int J Gen Med 2021: 14: 2491-2506.

3. Funke-Chambour M, Bridevaux PO, Clarenbach CF, Soccal PM, Nicod LP, von Garnier C. Swiss Recommendations for the Follow-Up and Treatment of Pulmonary Long COVID. Respiration 2021: 100: 826-841.

4. Myall KJ, Mukherjee B, Castanheira AM, Lam JL, Benedetti G, Mak SM, Preston R, Thillai M, Dewar A, Molyneaux PL, West AG. Persistent Post-COVID-19 Interstitial Lung Disease. An Observational Study of Corticosteroid Treatment. Ann Am Thorac Soc 2021: 18: 799-806.

5. Kostorz-Nosal S, Jastrzębski D, Chyra M, Kubicki P, Zieliński M, Ziora D. A prolonged steroid therapy may be beneficial in some patients after the COVID-19 pneumonia. Eur Clin Respir J 2021: 8: 1945186.

6. Segala FV, Sgalla G, Salvati F, Berardini L, Negri M, Nardella E, Potenza A, Murri R, Fantoni M. Adjunctive corticosteroid treatment for organizing pneumonia in COVID-19 patients with persistent respiratory failure. Respir Med 2021: 187: 106571.

7. Miller MR, Hankinson J, Brusasco V, Burgos F, Casaburi R, Coates A, Crapo R, Enright P, van der Grinten CP, Gustafsson P, Jensen R, Johnson DC, Maclntyre N, McKay R, Navajas D, Pedersen OF, Pellegrino R, Viegi G, Wanger J. Standardisation of spirometry. Eur Respir J 2005: 26: 319-338.

8. Holland AE, Spruit MA, Troosters T, Puhan MA, Pepin V, Saey D, McCormack MC, Carlin BW, Sciurba FC, Pitta F, Wanger J, Maclntyre N, Kaminsky DA, Culver BH, Revill SM, Hernandes NA, Andrianopoulos V, Camillo CA, Mitchell KE, Lee AL, Hill CJ, Singh SJ. An official European Respiratory Society/American Thoracic Society technical standard: field walking tests in chronic respiratory disease. Eur Respir J 2014: 44: 1428-1446.

9. Hinchcliff M, Beaumont JL, Thavarajah K, Varga J, Chung A, Podlusky S, Carns M, Chang RW, Cella D. Validity of two new patient-reported outcome measures in systemic sclerosis: Patient-Reported Outcomes Measurement Information System 29-item Health Profile and Functional Assessment of Chronic Illness Therapy-Dyspnea short form. Arthritis Care Res (Hoboken) 2011: 63: 1620-1628.

10. Patel AS, Siegert RJ, Brignall K, Gordon P, Steer S, Desai SR, Maher TM, Renzoni EA, Wells $A U$, Higginson IJ, Birring SS. The development and validation of the King's Brief Interstitial Lung Disease (K-BILD) health status questionnaire. Thorax 2012: 67: 804-810.

11. Sinha R, van den Heuvel WJ, Arokiasamy P. Validity and Reliability of MOS Short Form Health Survey (SF-36) for Use in India. Indian J Community Med 2013: 38: 22-26.

12. Petitpierre N, Cottin V, Marchand-Adam S, Hirschi S, Rigaud D, Court-Fortune I, Jouneau S, Israël-Biet D, Molard A, Cordier JF, Lazor R. A 12-week combination of clarithromycin and prednisone compared to a 24-week prednisone alone treatment in cryptogenic and radiationinduced organizing pneumonia. Sarcoidosis Vasc Diffuse Lung Dis 2018: 35: 230-238. 
13. Wu X, Liu X, Zhou Y, Yu H, Li R, Zhan Q, Ni F, Fang S, Lu Y, Ding X, Liu H, Ewing RM, Jones MG, Hu Y, Nie H, Wang Y. 3-month, 6-month, 9-month, and 12-month respiratory outcomes in patients following COVID-19-related hospitalisation: a prospective study. Lancet Respir Med 2021: 9: 747-754.

14. González J, Benítez ID, Carmona P, Santisteve S, Monge A, Moncusí-Moix A, GortPaniello C, Pinilla L, Carratalá A, Zuil M, Ferrer R, Ceccato A, Fernández L, Motos A, Riera J, Menéndez R, Garcia-Gasulla D, Peñuelas O, Bermejo-Martin JF, Labarca G, Caballero J, Torres G, de Gonzalo-Calvo D, Torres A, Barbé F. Pulmonary Function and Radiologic Features in Survivors of Critical COVID-19: A 3-Month Prospective Cohort. Chest 2021: 160: 187-198.

15. Shah AS, Wong AW, Hague CJ, Murphy DT, Johnston JC, Ryerson CJ, Carlsten C. A prospective study of 12-week respiratory outcomes in COVID-19-related hospitalisations. Thorax 2021: 76: 402-404. 